D.O.I.: $10.3895 / \mathrm{S} 1808-04482011000100006$

\title{
ANÁLISE ERGONÔMICA DO TRABALHO DE OPERADORES DE MÁQUINAS DE ESMALTAGEM - UMA COMPARAÇÃO ENTRE TECNOLOGIAS
}

\section{ERGONOMIC WORK ANALYSIS OF ENAMELLING MACHINES OPERATORS - A COMPARISON BETWEEN TECHNOLOGIES}

\author{
Fabiano Lucio dos Santos ${ }^{1}$; Francisco Antônio Pereira Fialho²; Ana Luisa Boavista Lustosa \\ Cavalcante $^{3}$ \\ ${ }^{1}$ Universidade Estadual de Londrina - UEL - Londrina - Brasil \\ fabiano_ergonomia@hotmail.com \\ ${ }^{2}$ Universidade Federal de Santa Catarina - UFSC - Florianópolis - Brasil \\ fialho@eps.ufsc.br \\ ${ }^{3}$ Universidade Estadual de Londrina - UEL - Londrina - Brasil \\ anaboavista@uel.br
}

\begin{abstract}
Resumo
Como conseqüencia da internacionalização dos mercados e o crescimento progressivo da concorrência industrial, empresas dos mais variados segmentos são "forçadas" a investirem cada vez mais no processo de produção, assim como no produto, com o menor custo possível. Como parte desta evolução, a transferência de tecnologia pode ser uma opção estratégica para o aumento da competitividade de uma indústria, porém, muitas vezes, esta inovação tecnológica pode não alcançar o resultado esperado do investimento. $O$ objetivo deste trabalho foi de realizar uma análise ergonômica da situação de trabalho de operadores de duas máquinas de esmaltagem, sendo uma de tecnologia mais antiga e outra mais moderna, fornecendo subsídios para traçar um comparativo com as características do trabalho entre as mesmas, sendo que ambas são operadas simultaneamente em um mesmo setor e pelos mesmos operadores. Para a viabilização do estudo foi utilizada a metodologia de análise ergonômica do trabalho proposta por Santos e Fialho (1997). Foi constatado que a não observação de condicionantes físicos, organizacionais e cognitivos durante a implantação de uma nova tecnologia pode acarretar em um aumento da carga de trabalho sobre o operador, assim como uma redução da produtividade causada por variáveis diversas.
\end{abstract}

Palavras-chave: análise ergonômica; esmaltagem; tecnologia.

\section{Introdução}

A Ergonomia é o estudo da concepção de ferramentas, máquinas, ambiente e tarefas seguindo os preceitos psicofisiológicos do ser humano, visando otimizar a relação homem - tarefa ambiente.

Uma das definições de ergonomia é colocada por Wisner (1987), onde se refere a tal ciência como um "conjunto de conhecimentos científicos relativos ao homem e necessários para a 
concepção de ferramentas, máquinas e dispositivos que possam ser utilizados com o máximo de conforto, segurança e eficácia".

Para a International Ergonomic Association (IEA), a Ergonomia é a disciplina científica que trata da compreensão das interações entre seres humanos e outros elementos de um sistema; que aplica teorias, princípios, dados e métodos; a projetos que visam otimizar o bem estar humano e a performance global do sistema.

De acordo com o Ergonomic Research Society (Inglaterra) a Ergonomia é o estudo do relacionamento entre o ser humano e os elementos do sistema produtivo e na aplicação de dados científicos sobre o homem de diferentes áreas de conhecimento, humanas, biomédicas, por exemplo, na solução dos problemas surgidos dessa interação (IIDA, 2005).

A realização de um confronto do trabalho prescrito, estabelecidos a partir de normas e procedimentos, com o trabalho real, modelado a partir da apreciação setorizada com foco nas atividades, resulta na perspectiva de um mapeamento de riscos, onde os próprios trabalhadores referem inadequações e queixas (ODDONE et al., 1986).

Conforme Guérin et al. (2001), para que o trabalhador realize a tarefa que lhe é prescrita, os indivíduos lançam mão de estratégias diversas, e como conseqüência, a saúde do trabalhador não pode ser abordada levando-se em conta apenas os fatores de risco em que os mesmos são expostos. Torna-se relevante observar o trabalhador na construção de modos operatórios que sejam favoráveis ao seu bem-estar.

Uma das definições para tecnologia é descrita por Perrow (1972) como sendo os meios de transformar as matérias-primas (sejam humanas, simbólicas ou materiais) em bens ou serviços desejáveis. Já Ong (1991) diz que tecnologia trata-se do conhecimento que o homem possui e que o torna capaz de desenvolver tarefas particulares.

Já inovação tecnológica é a aplicação de novos conhecimentos ao processo produtivo, resultando em um novo produto com alterações em algum atributo do anterior e/ou no grau de aceitação do produto pelo mercado, traduzindo-se, em geral, em uma elevação na lucratividade e/ou posicionamento da empresa no mercado (ROSENTHAL apud PROENÇA, 1996).

Segundo a Organização Internacional do trabalho - OIT (1988), a transferência de tecnologia se traduz pela exportação de tecnologia de um país a outro segundo diversas modalidades, tais como: construção de fábricas e plantas industriais completas; importação de equipamentos e componentes; financiamento de projetos de industrialização e infra- estrutura e envio de especialistas estrangeiros como consultores e formadores de pessoal local.

De acordo com Santos et al. (1997), é próprio da Antropotecnologia, assim como da Ergonomia, orientar-se para o trabalho, para as atividades daqueles que produzem. A abordagem busca o levantamento das causas, baseadas nos seus efeitos sobre a situação de trabalho. A partir 
dos resultados da análise do trabalho pode-se conceber uma árvore de causas, que permite assinalar as anomalias críticas do processo de trabalho. A diferença entre a Ergonomia e a Antropotecnologia é que a árvore de causas se limita, na Ergonomia, ao posto de trabalho ou, de modo mais amplo, à situação de trabalho. A Antropotecnologia objetiva a ampliação desta questão para permitir o entendimento do sistema de trabalho e do ambiente em que o mesmo se encontra.

A antropotecnologia preconiza em sua metodologia a harmonia dessas relações em casos que envolvam transferência de tecnologia por meio do estudo de fatores geográficos, sócioeconômicos, demográficos e antropológicos da região a ser implantada.

A análise da atividade real fornece dados fidedignos sobre a relação do operador com o ambiente de trabalho fornecendo subsídios-base para que possamos propor modificações que tragam benefícios, tanto para o funcionário, quanto para a empresa.

\section{Metodologia}

O estudo descrito foi realizado a partir da aplicação da metodologia de Análise Ergonômica do Trabalho proposta por Santos e Fialho (1995) em um setor de esmaltagem de uma empresa de produtos elétricos.

Neste setor, há o funcionamento de duas máquinas de esmaltagem, sendo uma de tecnologia mais antiga, de formato horizontal; e uma segunda máquina, de formato vertical e projeto atual.

$\mathrm{O}$ enfoque da análise ergonômica do processo de esmaltagem foi dado à máquina vertical, sendo posteriormente elaborado um comparativo entre tal situação de trabalho com o processo realizado da máquina horizontal, com o objetivo de destacar as diferenças entre tais tecnologias em relação aos aspectos físicos, organizacionais e cognitivos sobre os operadores.

Para a coleta de dados foram utilizadas entrevistas estruturadas direcionadas aos funcionários, líderes de produção e ao coordenador do setor, sendo que os demais dados foram registrados por meio de observação direta, filmagens, fotografias.

Para avaliação da sobrecarga biomecânica para algumas atividades foram utilizados os métodos semi-quantitativo Strain Index proposto por Moore e Garg (1995) e o método Owas (Ovako Working Posture Analisys System) utilizando o software WinOwas.

As condições do ambiente de trabalho referente a iluminância, temperatura e ruído foram avaliadas através do uso dos seguintes instrumentos: luxímetro digital portátil, modelo LX 101, da marca Lutronde; e de um termômetro digital de IBUTG da marca Wibget, modelo RSS-214; e dosímetro da marca Quest, modelo Q-300.

\section{Discussão}

\subsection{Caracterização da empresa e do setor avaliado}


A empresa onde foi realizado o estudo encontra-se na região sul do Brasil e faz parte do ramo eletro-eletrônico, estando em atividade há aproximadamente 40 anos.

O setor avaliado produz fios esmaltados para consumo interno, sendo estes destinados para outros setores da corporação. O processo de produção é contínuo, sendo que possui um total de oito colaboradores, distribuídos em três turnos, com um sistema de revezamento de cinco dias trabalhados por um de descanso.

Está localizada em uma cidade de pequeno porte, sendo que sua importância sócioeconômica fica evidenciada pelo fato de que é responsável pela renda, de forma direta e indireta, de aproximadamente $20 \%$ da população.

A tecnologia aplicada ao respectivo setor onde foi realizado o estudo é considerada avançada, sendo destaque em nível nacional pelo fato de existirem poucas máquinas similares no mercado. Há um estudo da equipe de planejamento estratégico da empresa com o intuito de adquirir mais uma máquina de esmaltagem vertical, ampliando a atuação da empresa no mercado. A máquina de esmaltagem vertical e a horizontal estão dispostas em paralelo, e entre as duas máquinas será implantada uma segunda máquina vertical; como pode ser visualizado no leiaute futuro do setor na Figura 1:

Figura 1: Leiaute do setor de Esmaltagem de Fios

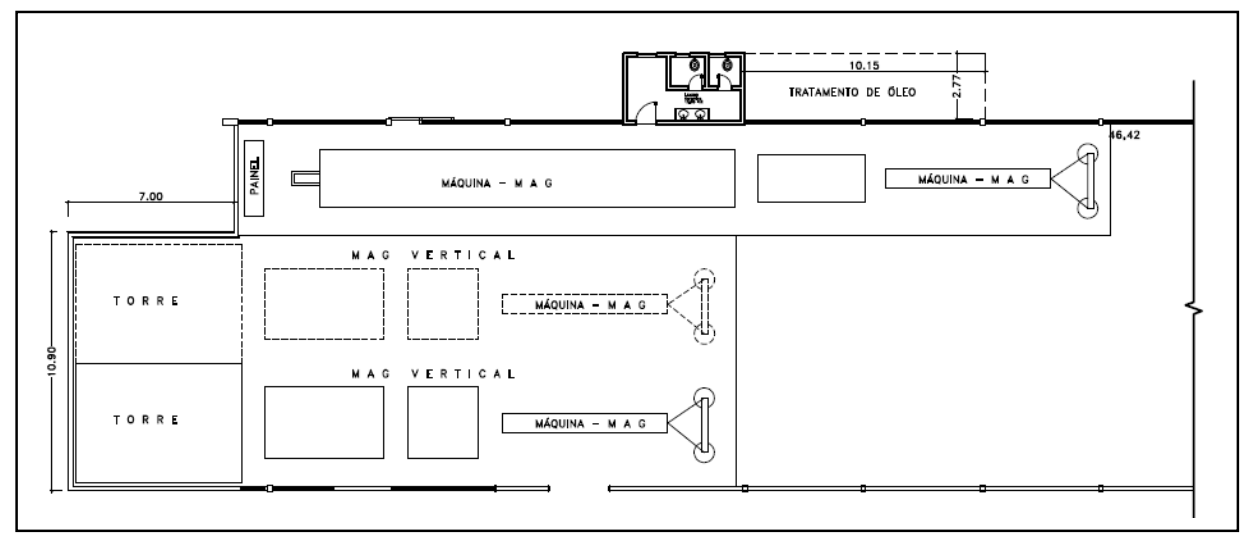

Fonte: Empresa (2008)

A gestão de pessoas ocorre de maneira predominantemente participativa, sendo facilitada pela localização da empresa em um pequeno município. Os funcionários são bastante familiarizados uns com os outros.

\subsection{Análise da demanda}

A demanda por uma intervenção ergonômica no determinado setor foi de caráter explícito; resultado da preocupação da direção industrial da respectiva empresa baseada em dois motivos diferentes: 
a) A identificação, avaliação e tratamento de aspectos que afetassem negativamente a produção com a implantação desta uma nova tecnologia, devido à aquisição de uma máquina de esmaltagem mais moderna do que a que se encontra em operação;

b) A preocupação em se adequar à legislação trabalhista vigente, no caso, a Norma Regulamentadora $\mathrm{n}^{\mathrm{o}} 17$ - que recomenda a elaboração da Análise Ergonômica do Trabalho, evitando assim um possível passivo trabalhista pela falta da presença de tal avaliação:

“17.1.2. Para avaliar a adaptação das condições de trabalho às características psicofisiológicas dos trabalhadores, cabe ao empregador realizar a análise ergonômica do trabalho, devendo a mesma abordar, no mínimo, as condições de trabalho, conforme estabelecido nesta Norma Regulamentadora (BRASIL, 1990).

Baseando-se nestes pontos, houve o acionamento do SESMT (Serviço Especializado em Saúde e Segurança do Trabalho) para que esta análise pudesse ser elaborada, e assim, atingindo tais resultados esperados.

\subsection{Análise da tarefa}

\subsubsection{Dados referentes à população}

O setor de esmaltagem é operado por dois operadores por turno, sendo que cada um é responsável pela operação de uma das duas máquinas (a vertical e a horizontal).

Dos oito operadores que formam o efetivo da produção, todos são do sexo masculino e possuem no máximo o $2^{\circ}$ grau completo. A maioria dos operadores do setor possuem mais de 5 anos de contrato de trabalho com a empresa, sendo que alguns são contratados há mais de 15 anos, como pode ser constatado no Gráfico 1:

Gráfico 1: Tempo de trabalho no setor

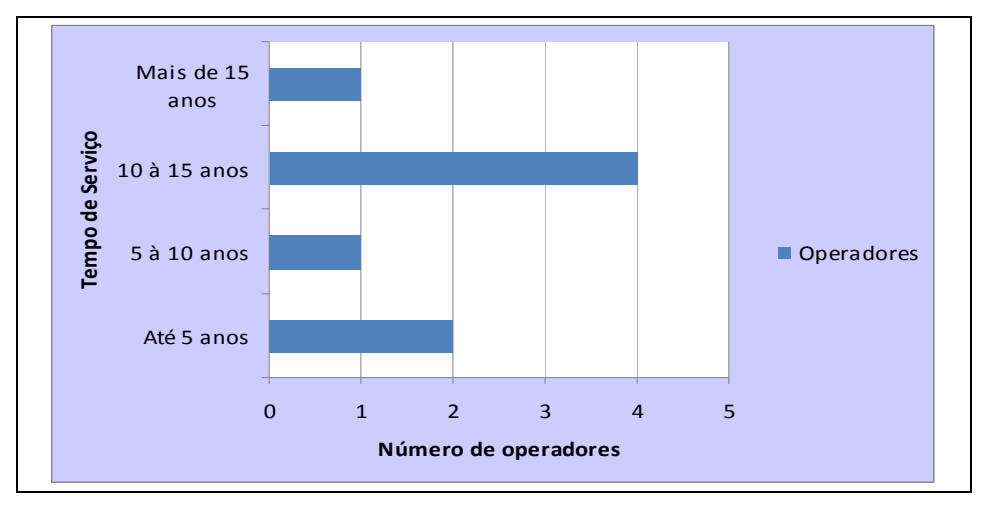

Fonte: Pesquisa de campo (2008)

Tais operadores são divididos em três turnos e trabalham em um sistema de 
revezamento $5 / 1$.

Os turnos são divididos em:

$1^{\circ}$ turno: 05:25 às 10:00 - 11:00 às 13:42;

$2^{\circ}$ turno: $13: 42$ às 18:00 - 19:00 às 22:00;

$3^{\circ}$ turno: 22:00 às 02:00 - 03:00 ás 05:25.

Os níveis de turn-over e absenteísmo são insignificantes.

\subsubsection{Dados referentes à máquina}

A máquina possui basicamente dois processos: primeiramente ocorre a trefilação do fio e, na sequência a esmaltagem do mesmo. No setor avaliado, existem duas máquinas que realizam tal processo: uma mais antiga, de formato horizontal que possui 15 metros de comprimento por 2 de largura; e a outra máquina, esta mais atual, que possui um formato vertical com 25 metros de altura e 5 de largura. As duas máquinas oferecem um alcance das alavancas e botões dentro da zona de conforto das articulações de membros superiores.

Ambas as máquinas são operadas por meio de software, sendo que tais comandos são oferecidos na língua inglesa. A programação da máquina é feita somente quando há troca da especificação do fio. Ambas as máquinas foram importadas da Áustria.

O setor onde foi desenvolvido o estudo é responsável pela produção de fios esmaltados que serão utilizados na fabricação de bobinas, sendo que tal produção é destinada para consumo interno.

A principal vantagem da máquina vertical é que essa tem a capacidade de esmaltar fios mais espessos. Esta variedade de fio não pode ser esmaltada na máquina horizontal, pois a força da gravidade compromete a isolação do fio, podendo causar ruptura e, consequentemente, uma esmaltagem de baixa qualidade.

\subsubsection{Método prescrito}

Dentre as ações técnicas que devem ser realizadas pelos operadores, relativas ao processo de esmaltagem, comuns às duas máquinas estão:

- A consulta sobre a ordem de fabricação;

- Acompanhamento da programação e a montagem do fio nas linhas;

- Execução do processo de esmaltagem seguindo a sequência correta de montagem das fieiras da trefila e das fieiras da esmaltagem, conforme descrição do projeto;

- Acompanhamento do processo produtivo, observando o correto posicionamento do fio, o correto bobinamento do fio, a correta posição do fio na entrada do forno de recozimento,

\footnotetext{
${ }^{1}$ Cinco dias trabalhados por um dia de descanso.
} 
o alinhamento dos fios na polia principal, a troca de carretéis quando cheios;

- Inspecionar o produto de acordo com os padrões adotados.

Para que haja otimização do processo, seguem alguns cuidados:

- Seguir rigorosamente a seqüência das fieiras da trefila e da esmaltagem;

- Verificar se as fieiras estão limpas;

- Durante o processo de montagem devem-se lubrificar as fieiras com óleo de trefilação para não danificar as mesmas;

- Abrir o registro do esmalte a partir do momento em que o fio esteja totalmente montado e limpo.

\subsubsection{Dados referentes ao meio ambiente}

O barracão onde se encontra a máquina não possui sistema de climatização, sendo que não há janelas que dão acesso à ventilação externa. A mensuração da temperatura ambiente foi realizada por meio da utilização de um termômetro de bulbo úmido, durante o período vespertino de um dia pertencente à estação da primavera, obtendo-se um valor de $27,1^{\circ} \mathrm{C}$.

Em relação ao ruído, sua mensuração foi realizada com um dosímetro, apresentando o valor de 71,8 decibéis.

Por meio de um luxímetro foi registrado o valor de 230 lux.

No quadro 1 são expostas algumas diferenças entre o funcionamento da máquina vertical e da horizontal:

Quadro 1- Comparativo da análise da tarefa da máquina vertical x horizontal

\begin{tabular}{|c|c|c|}
\hline $\begin{array}{l}\text { Diferenças relevantes da } \\
\text { tarefa }\end{array}$ & Máquina vertical & Máquina horizontal \\
\hline Função da máquina & $\begin{array}{l}\text { Esmaltagem de fios finos e de fios } \\
\text { espessos. }\end{array}$ & Esmaltagem de fios finos. \\
\hline Dimensionamento & $\begin{array}{l}\text { Máquina vertical com } 25 \text { metros de } \\
\text { comprimentos e possui uma escada de } \\
\text { acesso à torre com } 6 \text { lances de escada com } \\
14 \text { degraus cada. } \\
\text { A escada apresenta degraus muito estreitos, } \\
\text { com risco de queda. }\end{array}$ & $\begin{array}{l}\text { Máquina na horizontal, com } 15 \text { metros de } \\
\text { comprimento; } \\
\text { Não há necessidade de subir escadas. }\end{array}$ \\
\hline Vantagens & $\begin{array}{l}30 \% \text { mais rápida que a horizontal, em } \\
\text { média; produzindo um carretel a cada } 20 \\
\text { minutos. Ocupa menos espaço físico (a } \\
\text { máquina antiga é horizontal) e produz fios } \\
\text { grossos. As variáveis: temperatura; }\end{array}$ & $\begin{array}{l}\text { Não produzia fio grosso, pois a ação da } \\
\text { gravidade resulta na formação de "barriga" }{ }^{2,} \text { no } \\
\text { trajeto do fio, resultando em má qualidade no } \\
\text { produto (ruptura do isolamento do esmalte). } \\
\text { Demanda de } 30 \text { a } 40 \text { minutos em média para a }\end{array}$ \\
\hline
\end{tabular}




\begin{tabular}{|c|c|c|}
\hline & $\begin{array}{l}\text { velocidade e tensão são reguladas de forma } \\
\text { automática pela máquina. }\end{array}$ & $\begin{array}{l}\text { produção de um carretel. As variáveis: } \\
\text { temperatura; velocidade e tensão são reguladas } \\
\text { de forma manual. }\end{array}$ \\
\hline Software & $\begin{array}{l}\text { Há dois computadores: um que comanda o } \\
\text { funcionamento da máquina (temperatura, } \\
\text { velocidade) e o outro controla a qualidade } \\
\text { do produto, fornecendo tais dados em forma } \\
\text { de gráficos. Funções em inglês; } \\
\text { Há algumas funções novas; } \\
\text { Tempo de adaptação (questão de } \\
\text { aprendizado, de capacitação - causando } \\
\text { uma maior chance de ocorrência de erros). }\end{array}$ & $\begin{array}{l}\text { Há apenas um computador, que controla o } \\
\text { funcionamento e a qualidade de forma } \\
\text { conjugada. Funções em inglês; } \\
\text { Problema técnico de interface visual: "tela } \\
\text { escura" que dificulta a tomada de informações } \\
\text { pelo operador. } \\
\text { Os operadores relataram que memorizaram a } \\
\text { programação da máquina. }\end{array}$ \\
\hline Mão de obra & $\begin{array}{l}\text { Necessidade de um operador por turno. } \\
\text { Possuem pouco conhecimento de língua } \\
\text { inglesa e informática. }\end{array}$ & Idem. \\
\hline Problemas técnicos & $\begin{array}{l}\text { Ocorrem com frequência, devido ao pouco } \\
\text { tempo de funcionamento. Há um alarme } \\
\text { (visual e sonoro) que é ativado quando o } \\
\text { processo é interrompido. Problemas mais } \\
\text { complexos de software são resolvidos por } \\
\text { conexão online com a fabricante. }\end{array}$ & $\begin{array}{l}\text { Também possui um sistema de alarme, porém } \\
\text { erros de processo são mais raros. }\end{array}$ \\
\hline Setup & $\begin{array}{l}\text { Setup com tempo médio de } 1,5 \text { horas. É } \\
\text { mais rápida porque as variáveis: } \\
\text { velocidade, temperatura e tensão, são } \\
\text { reguladas de forma automática pela } \\
\text { máquina. }\end{array}$ & \begin{tabular}{|l} 
Média de 2 horas. Mais lenta porque tais \\
variáveis são reguladas de forma manual.
\end{tabular} \\
\hline Sucata & $\begin{array}{l}\text { Pelo setup ser mais curto gera menor } \\
\text { quantidade de refugos. Isto se deve pela } \\
\text { automação de algumas variáveis. }\end{array}$ & Maior quantidade de refugos. \\
\hline Método & $\begin{array}{l}\text { Houve alguns episódios de realização de } \\
\text { regulagens erradas feitas pelos operadores; } \\
\text { É necessário } 1 \text { (um) operador para manter a } \\
\text { máquina em funcionamento, e quando há a } \\
\text { necessidade de montá-la são necessários } 2 \\
\text { operadores por turno (processo contínuo); } \\
\text { A "montagem da máquina" (termo utilizado } \\
\text { pelos operadores para colocar as máquinas } \\
\text { em condições de funcionamento) é feita } \\
\text { sempre quando há troca da especificação do } \\
\text { produto ou quando há uma quebra do fio. }\end{array}$ & Idem. \\
\hline Erros & $\begin{array}{l}\text { Precisa ter cautela com relação à limpeza, } \\
\text { pois o pó do alumínio libera muita sujeira } \\
\text { (borra); e os operadores não estão } \\
\text { acostumados em realizar, frequentemente, } \\
\text { esta limpeza. } \\
\text { Falta de comunicação e confiabilidade. } \\
\text { Problemas relacionados à usabilidade do } \\
\text { software (baixo conhecimento em } \\
\text { informática e em língua inglesa). }\end{array}$ & Necessidade da limpeza é esporádica. \\
\hline Queixas e acidentes & $\begin{array}{l}\text { Calor intenso, principalmente na troca de } \\
\text { fieiras. }\end{array}$ & Nenhuma. \\
\hline
\end{tabular}




\begin{tabular}{||l|l||l||}
\hline \multicolumn{1}{|l||}{} & $\begin{array}{l}\text { Incidente: Queimadura no braço com } \\
\text { solvente ao trocar as fieiras (já foi trocado } \\
\text { por um menos agressivo) e foi } \\
\text { recomendado o uso de mangote nos braços. }\end{array}$ & \\
\hline \hline Matéria-prima & Fios de alumínio e cobre. & Idem, porém não esmalta fios grossos de \\
alumínio.
\end{tabular}

Fonte: Pesquisa de campo (2008-2009)

\subsection{Análise da atividade}

A seqüência das atividades realizadas, também comuns tanto para a máquina vertical como para a horizontal, estão descritas a seguir:

a) Alimentar a máquina com o cesto de fios de alumínio ou cobre;

b) Soldar o fio do cesto novo com a ponta do fio que está na máquina;

c) Montar as fieiras da trefila;

d) Montar as fieiras da esmaltagem

e) Abastecer a máquina com esmalte e solvente;

f) Passar o fio entre os fornos;

g) Programar a máquina;

h) Monitorar o funcionamento do processo.

Quanto à atividade realizada processo de trabalho da máquina de esmaltagem vertical, as principais dificuldades relatadas pelos operadores são:

- Gasto energético importante para subir as escadas para a "montagem" da máquina 
(quando ocorre a troca de programação ou quebra do fio);

- Movimentar os cestos de fios de cobre requer maior esforço físico de que os cestos de fios de alumínio, já que a movimentação do cesto de fio é feita utilizando uma paleteira manual;

- Trocar as fieiras, pois exige uma carga mental importante por parte do operador, pelo fato das diferentes fieiras serem semelhantes;

- Operar o software com informações em inglês, durante as trocas de programação, o que pode induzir ao erro devido à complexidade do sistema, já que o operador tem um conhecimento limitado tanto ao idioma, quanto à informática, aumentando assim a carga mental dos funcionários;

- Retirar os carretéis de fios de cobre que pesam em torno de $20 \mathrm{Kg}$, associado a uma flexão de tronco de 45 à $60^{\circ}$ torna o esforço físico maior;

- É necessário a pesagem de todos os carretéis de fios produzidos, e para isso o operador precisa se deslocar a uma distância de aproximadamente 15 metros até a única balança do setor, que se encontra ao lado da máquina de esmaltagem horizontal;

- As escadas com degraus estreitos, aumentando o risco de acidentes durante a subida ou descida dos operadores. Ela possui com 6 lances com 14 degraus cada, com largura de $700 \mathrm{~mm}$, espelho com $170 \mathrm{~mm}$ e profundidade de $160 \mathrm{~mm}$;

- Há desconforto térmico nos dias com temperatura mais elevada, pois não há janelas ou sistema de climatização no setor;

Há problemas ainda não identificados na matéria-prima que fazem com que determinadas especificações do fio de alumínio arrebentem com certa freqüência, demandando mais carga de trabalho sobre os operadores.

No quadro 2 são apresentadas algumas diferenças relevantes entre a atividade desempenhada na operação da máquina vertical e da máquina horizontal:

Quadro 2 - Comparativo da análise da atividade da máquina vertical x horizontal

\begin{tabular}{||l||l||l||}
\hline \hline Diferenças relevantes da atividade & \multicolumn{1}{|c||}{ Máquina vertical } & Máquina horizontal \\
\hline \hline \multirow{5}{*}{ Setup } & O operador precisa subir as escadas & \\
& para "montar" a máquina quando o & \\
fio arrebenta (média de 2x/turno) ou \\
quando há troca da especificação do \\
fio (1x/dia, em média); o que \\
demanda grau de esforço físico \\
importante para subir e descer os 84 \\
degraus. Ainda há o agravante dos \\
degraus serem estreitos, o que pode \\
predispor os operadores a acidentes.
\end{tabular}




\begin{tabular}{|c|c|c|}
\hline $\begin{array}{l}\text { Abastecimento da máquina com os } \\
\text { cestos de fios }\end{array}$ & $\begin{array}{l}\text { A esmaltagem é feita, principalmente } \\
\text { de fios de alumínio, sendo que os } \\
\text { cestos são mais leves. }\end{array}$ & $\begin{array}{l}\text { Há um maior esforço físico para } \\
\text { movimentar os cestos de fios de cobre } \\
\text { dos que os cestos de fios de alumínio, } \\
\text { já que a movimentação do cesto de } \\
\text { fio é feita utilizando uma paleteira } \\
\text { manual. }\end{array}$ \\
\hline Mão de obra & $\begin{array}{l}\text { Durante a troca por outro tipo de fio } \\
\text { ou quando o mesmo arrebenta, o } \\
\text { operador da máquina horizontal } \\
\text { auxilia o operador da máquina } \\
\text { vertical. } \\
\text { Os operadores iniciaram estudos de } \\
\text { informática básica após mais de um } \\
\text { ano de funcionamento da nova } \\
\text { máquina, o que pode reduzir a } \\
\text { ocorrência de erros e a carga mental } \\
\text { sobre o operador em momentos que o } \\
\text { mesmo precisa programar o software. }\end{array}$ & $\begin{array}{l}\text { Durante a troca por outro tipo de fio } \\
\text { ou quando o mesmo arrebenta, o } \\
\text { operador da máquina vertical auxilia } \\
\text { o operador da máquina horizontal. } \\
\text { Aparentemente possuem um bom } \\
\text { conhecimento empírico sobre o } \\
\text { software. }\end{array}$ \\
\hline Pesagem dos carretéis & $\begin{array}{l}\text { O operador que está operando a } \\
\text { máquina vertical desloca-se por uma } \\
\text { distância de aproximadamente } 15 \\
\text { metros para pesar os carretéis de fio } \\
\text { na balança da máquina de } \\
\text { esmaltagem horizontal. }\end{array}$ & O deslocamento é de 2 metros. \\
\hline Alarmes & $\begin{array}{l}\text { Quando a máquina pára por } \\
\text { problemas técnicos ou quando há a } \\
\text { necessidade de troca do carretel, há } \\
\text { um sinal luminoso que dispara e } \\
\text { permanece por um período aceso, e } \\
\text { após alguns segundos é iniciado um } \\
\text { sinal sonoro. }\end{array}$ & 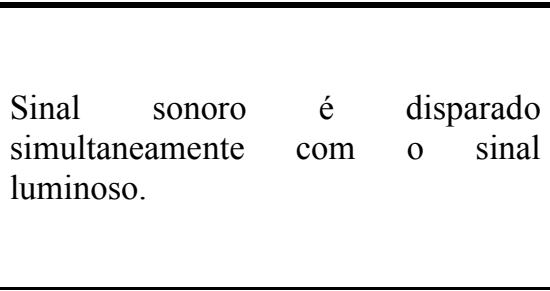 \\
\hline Fatores ambientais & $\begin{array}{l}\text { Há sobrecarga térmica em dias com } \\
\text { temperaturas mais elevadas, devido à } \\
\text { ausência de ventilação natural ou } \\
\text { artificial. }\end{array}$ & Idem. \\
\hline Organização do trabalho & $\begin{array}{l}\text { Os funcionários fazem uma sessão } \\
\text { diária de ginástica laboral } \\
\text { preparatória com duração de } 10 \\
\text { minutos. Segundo entrevista com os } \\
\text { colaboradores, os mesmos relataram } \\
\text { bom relacionamento com os líderes e } \\
\text { ausência de horários pré- } \\
\text { determinados para necessidades } \\
\text { fisiológicas. }\end{array}$ & Idem. \\
\hline
\end{tabular}

Fonte: Pesquisa de campo (2008-2009)

Ao avaliar a atividade de montagem das fieiras e da esmaltagem, foi utilizada ferramenta ergonômica semi-quantitativa de Moore e Garg para avaliar a sobrecarga músculo-esquelética em nível de membros superiores (Figura 2). 
Figura 2: Aplicação da ferramenta semi-quantitativa de Moore-Garg para avaliar membros superiores

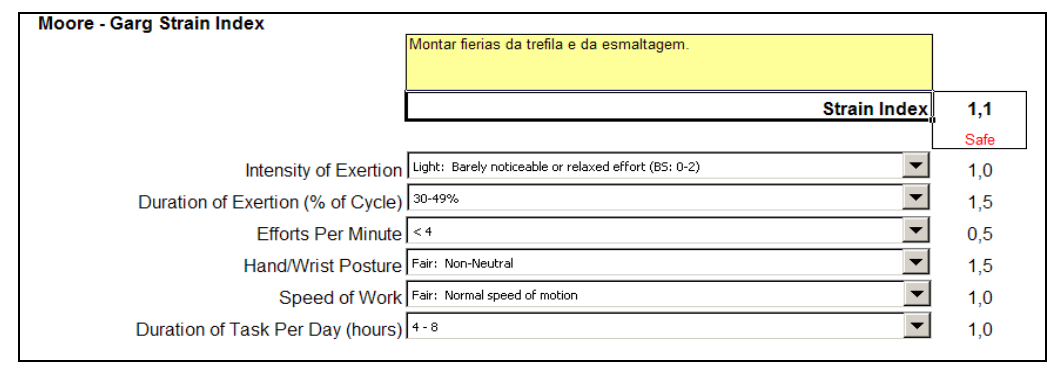

Fonte: Moore e Garg (1995)

Como resultado, a ação técnica de montar as fieiras da trefila e da esmaltagem apresentaram um baixo risco para o desenvolvimento e/ou agravamento de distúrbios osteomusculares em membros superiores.

Para avaliar a sobrecarga física dos operadores durante a ação técnica de "retirar o carretel de fio esmaltado da máquina”, foi aplicada a ferramenta OWAS - Ovako Working Posture Analysis System (Figura 3).

Figura 3: Aplicação da ferramenta OWAS para avaliar membros superiores e coluna vertebral

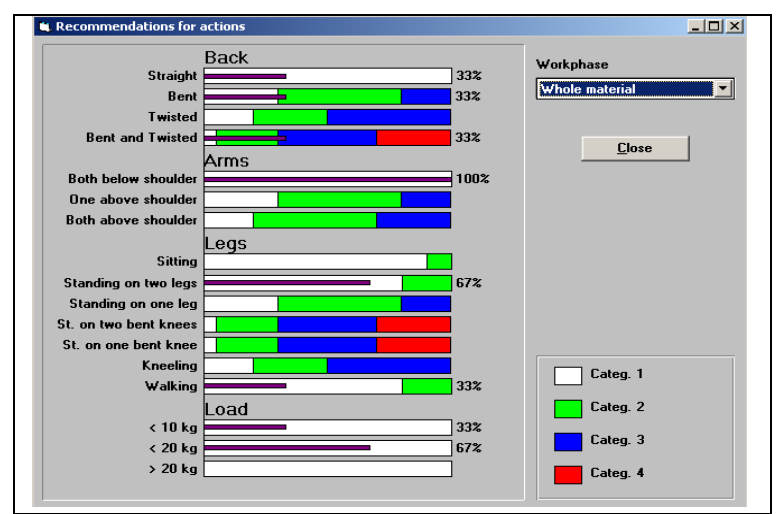

Fonte: Tampere University Technology (1996)

Como resultado, a ação técnica de manusear o carretel de fio resultou em um risco moderado para o desenvolvimento e/ou agravamento de distúrbios osteomusculares em coluna vertebral, principalmente a região lombar.

\subsection{Diagnóstico ergonômico}

Com base na Análise Ergonômica realizada no setor estudado, podem-se evidenciar algumas condicionantes que devem ser observadas pela supervisão e pelo SESMT para oferecer melhores condições de trabalho aos operadores, quanto à Saúde e Segurança do Trabalho, além de um incremento da produtividade para a corporação.

A escada que dá acesso ao topo da torre da máquina de esmaltagem vertical possui degraus com pisada de $160 \mathrm{~mm}$. A média de 2 a 3 vezes que o funcionário necessita subir as escadas por 
turno, predispõe o mesmo a acidentes por queda e quanto maior esta frequência, torna maior o risco de acidentes.

Observa-se que a mão de obra não é especializada e não possui treinamento suficiente. Os operadores possuem conhecimentos superficiais sobre informática e língua inglesa, sendo que há ocorrências de problemas no funcionamento da máquina que exigem alguma tomada de decisão fora da rotina dos operadores, o que pode acarretar em erros e acidentes, além de sobrecarga mental.

Quanto aos fatores ambientais, as medições referentes a temperatura apresentaram um valor de $27,1^{\circ} \mathrm{C}$ no verão, causando desconforto térmico aos operadores. Quando é necessário subir as escadas que levam até a torre, ocorre um aumento da sobrecarga física dos operários, principalmente associado a atividade de montagem da máquina durante alguma quebra do fio ou troca de especificação.

Dependendo da qualidade da matéria-prima utilizada pode ocasionar um incremento na carga de trabalho sobre os operadores, devido ao fato de que um fio de alumínio que não esteja em boas condições pode romper-se mais facilmente, aumentando a frequência com que os operadores precisam na montagem da máquina. Isto demanda subida e descida das escadas da torre da máquina vertical.

Uma ação que habitualmente é tomada por parte dos operadores é de selar a saída sonora do alarme de parada da máquina com uma fita adesiva, para evitar o ruído emitido quando há alguma parada intempestiva da máquina por problema mecânico ou quando há troca de carretéis; o que pode gerar perda de produtividade, já que muitas vezes o alarme visual não é percebido.

Além do esforço físico despendido na "montagem da máquina”, o operador tem dificuldades em movimentar os cestos de fios, principalmente os de cobre, já que no equipamento é utilizada uma paleteira manual.

\subsection{Recomendações}

A seguir são descritas ações para a otimização das atividades neste posto de trabalho que fazem parte de um caderno de encargos embasado no confronto da análise da atividade prescrita com a atividade real (Quadro 3):

Quadro 3- Recomendações ergonômicas

\begin{tabular}{||l||c||}
\hline Aspectos & Ações Ergonômicas \\
\hline
\end{tabular}




\begin{tabular}{||l||l||}
\hline \multirow{5}{*}{ Técnicos } & $\begin{array}{l}\text { Avaliar a possibilidade da aquisição de uma matéria-prima de maior qualidade, } \\
\text { estudando a relação custo-benefício do uso de um produto mais barato com as } \\
\text { paradas da máquina e o esforço físico dos operadores. } \\
\text { Estudar a viabilidade de ergodesign da escada de acesso ao topo da máquina de } \\
\text { esmaltagem vertical, utilizando dados antropométricos e normas da ABNT, } \\
\text { garantindo uma melhor acessibilidade. }\end{array}$ \\
\hline \hline \multirow{3}{*}{ Organizacionais } & $\begin{array}{l}\text { Capacitar a mão de obra com relação aos conhecimentos sobre informática; } \\
\text { Treinamento sistematizado para operar o software da máquina; } \\
\text { Treinamento de manuseio de cargas (recomendação da NR-17) assim como os } \\
\text { devidos treinamentos de reciclagem quanto a estes assuntos. } \\
\text { Orientar os operadores quanto às normas de produção em relação ao } \\
\text { funcionamento adequado dos alarmes. }\end{array}$ \\
\hline \hline \multirow{3}{*}{ Ambientais } & $\begin{array}{l}\text { Otimizar os níveis de temperatura ambiental com a implantação de ventiladores ou } \\
\text { umidificadores de ar. }\end{array}$ \\
\hline \hline \multirow{3}{*}{ Instrumentais } & $\begin{array}{l}\text { Disponibilizar uma balança para pesagem dos carretéis de fios esmaltados próxima } \\
\text { da máquina vertical, evitando que o operador tenha que se deslocar por 15 metros } \\
\text { até a balança da máquina horizontal. } \\
\text { Disponibilizar uma paleteira elétrica para evitar o esforço físico gerado durante a } \\
\text { atividade de movimentação dos cestos de fios, principalmente os de fios de cobre. }\end{array}$ \\
\hline \hline
\end{tabular}

Fonte: Pesquisa de campo (2009)

\section{Conclusão}

Como preconiza os aspectos antropotecnológicos descritos por Santos et al (1997), a implantação de uma inovação tecnológica deve ser estudada minuciosamente em todas as suas fases, com o objetivo de otimizar a sua produtividade, assim como oferecer conforto e segurança para o trabalhador.

A metodologia da Análise Ergonômica do Trabalho aponta condicionantes que poderão causar sobrecarga física ou mental aos operadores, podendo refletir negativamente na produtividade de uma empresa: aumento nos índices de absenteísmo, refugos, retrabalhos, passivos trabalhistas e outros. Sua utilização pode atenuar alguns efeitos indesejados de um processo de transferência de tecnologia.

Embora grande parte destes condicionantes seja claramente observável, isto pode ser detectado somente por meio de uma avaliação criteriosa da situação real de trabalho, pois assim é possível observar as variabilidades normais e/ou incidentais atuantes sobre os funcionários. 


\begin{abstract}
As a result of the internationalization of markets and the progressive growth of industrial competition, companies from many different segments are "forced" to increasingly invest in the production process, as well as in the product with the lowest possible cost. As part of this development, technology transfer can be a strategic option for increasing the competitiveness of an industry, but often this technological innovation cannot achieve the expected result of the investment. The objective of this paper was to do an ergonomic analysis of the work situation of operators of two enamelling machines, one for older technology and another more modern, providing subsidy to draw a comparison with the characteristics of labor between them, and both are operated simultaneously in the same sector and by the same operators. For the feasibility study methodology was used ergonomics work analysis proposed by Santos and Fialho (1997). It was found that the non-observation of physical constraints, organizational and cognitive while deploying a new technology may result in an increased workload on the operator as well as a reduction in productivity caused by several variables.
\end{abstract}

Key-words: ergonomics work analysis; enamelling; technology.

\title{
Referências
}

BRASIL. Norma Regulamentador n⿳ 17: Portaria n 375 de 23 de novembro de 1990.

GUÉRIN et al. Compreender o trabalho para transformá-lo: a prática da ergonomia. São Paulo: Editora Edgard Blucher, 2001.

IEA - Revista Ação Ergonômica. Volume 3, Número 2, set/2008. ISSN 1519-7859 GENTE - Grupo de Ergonomia e Novas Tecnologias (COPPE/UFRJ).

IIDA, I. Ergonomia: projeto e produção. 2a Edição. São Paulo: Editora Edgard Blucher, 2005.

MOORE, J.; GARG, A. The strain index: a proposed method to analyse jobs for risk of distal upper extremity disorders. American Industrial. Hygiene Association Journal. United States, v. 56, n. 5, 1995.

ODDONE, I.; GASTONE, M.; GLORIA, S. et al. Ambiente de trabalho: a luta dos trabalhadores pela saúde. São Paulo: Hucitec, 1986.

OIT. Seguridad, salud y condiciones de trabajo en transferencia de tecnologia a los paises en desarrollo. Repertorio de recomendaciones praticas. Ginebra (Suiza): Organización Internacional del Trabajo, 1988.

ONG, C-N. Ergonomics, technology transfer and developing countries. Ergonomics, v.34, n.6, 1991. cross ${ }^{\text {eef }}$

PERROW, C.B. Análise organizacional: um enfoque sociológico. São Paulo: Atlas, 1976.

PROENÇA, R. P. C. Aspectos organizacionais e inovação tecnológica em processos de transferência de tecnologia: uma abordagem antropotecnológica no setor de alimentação coletiva. Tese (Doutorado em Engenharia) (PPGEP/ UFSC, Florianópolis, Brasil), 1996.

SANTOS, N.; FIALHO, F. A. P. Manual de Análise Ergonômica do Trabalho. $2^{\text {a }}$ Edição. Curitiba: Editora Gênesis, 1997.

SANTOS, N. et al. Antropotecnologia, a ergonomia dos sistemas de produção. Curitiba: Gênesis, 1997.

STRAIN INDEX. Software de auxílio ao método de Moore e Garg. Disponível em:< www.hsc.usf.edu/ $\sim$ tbernard> Acesso em: 04 mar. 2009.

WINOWAS. Software de auxílio ao método $\boldsymbol{O W A S}$. Disponível em: <http://turva1.me.tut.fi/owas/>. Acesso em: 02 mar. 2009.

WISNER, A. Por dentro do Trabalho - Ergonomia: método e técnica. Tradução Flora Maria Gomide Vezzá. São Paulo: FDT: Oboré, 1987. 
Filiação institucional: Romagnole Produtos Elétricos S.A.

Departamento: SESMT

Função ou cargo ocupado: Fisioterapeuta do Trabalho e Ergonomista

Endereço completo para correspondência: Rua Hawaí, 310 - Maringá PR; CEP: 87040-160.

Telefones para contato: (44) 99128360; (44) 30343552

e-mail:fabiano_ergonomia@hotmail.com

Nome completo: Francisco Antônio Pereira Fialho

Filiação institucional: Universidade Federal de Santa Catarina

Departamento: DEGC

Função ou cargo ocupado: Professor associado

Endereço completo para correspondência: Rua Duarte Shutel, 262, AP. 1003, CEP: 88.017-640,

Florianópolis, SC.

Telefones para contato: 4884049139

e-mail:fialho@eps.ufsc.br

Nome completo: Ana Luisa Boavista Lustosa Cavalcante

Filiação institucional: Universidade Estadual de Londrina

Departamento: Design

Função ou cargo ocupado: Docente

Endereço completo para correspondência: Rua Arapongas, 79, Londrina, PR

Telefones para contato: 43 9932-5252, 43 3371-4479

e-mail:anaboavista@uel.br

Enviado em: 27/08/2009

Aprovado em: 03/02/2011 